\title{
Language Characteristics and Written Requirements of the Maritime English Correspondence
}

\author{
Jiang Shen \\ Dalian Maritime University, Dalian 116026, China \\ Tel: 86-411-8472-9640Ｅ-mail: shenjiang@dl.cn \\ Zhenhua Zhao \\ Pilot Station, Port of Huanghua, Cangzhou 061110, China \\ Tel: 86-0317-538-7839 E-mail: lingyun-007@yeah.net
}

\begin{abstract}
Aiming at the requirements of the maritime English correspondence, the language characteristics of the maritime English correspondence are analyzed in this article, and the factors influencing the written skills of the maritime English correspondence are discussed, and the principles of " $7 \mathrm{C}$ " including the courtesy, the consideration, the completeness, the conciseness, the clarity, the concreteness, and the correctness should be utilized in the written of the maritime English correspondence, and the contents are listed in one complete maritime English correspondence, with their functions, that could help to enhance maritime staffs' written capacity.
\end{abstract}

Keywords: Maritime English correspondence, Principles of "7C", Written, Conciseness

\section{Introduction}

The shipping industry involves many countries and departments, with international characters, and the maritime English is the work language in the shipping industry, and employees associate each other by English, so the employees in the shipping industry must grasp corresponding language ability. The English ability includes spoken English, reading English, and written English, but spoken English and dialog are only applied in both sides' meetings or voice communication, and in more instances, both sides could not meet or talk frequently, and those important things must be communicated or recorded by written form, and both parties engaging in the international shipping service usually live far apart from each other, and they could not meet in most instances, and employees always judge the others' professional ability and service level, and a serious and decent English correspondence (from content to form) could leave good expression to the other, and it could pave the way for establishing the business relationship. In the shipping industry, most businesses are large, and for the parties who never met, a worse correspondence from form to phrase would make the other to doubt the ability, so it is hard to image who would negotiate with the person who could not write good maritime English correspondence. As the most important written communication tool, the maritime English correspondence (including E-mail, letter, and fax) occupies very important status in the maritime English.

China is the third largest imports and exports country in the world and the maritime shipping is the uppermost transportation mode. At the same time, China is the big shipping country, with about four thousand maritime ships sailing in the world, and many employees engage in the shipping industry or the relative industry, so the maritime English correspondence writing is one important content in the maritime English course system, and the students in the maritime colleges must grasp the written requirements of the maritime English correspondence. However, many ship-owners complained Chinese shipmen's bad English ability, and many Chinese shipping enterprises could not effectively communicate with foreign shipping enterprises or produce many misunderstandings because of bad English ability, so the employees in the shipping industry should know the language characters and written requirements of the maritime English correspondence, and write the maritime correspondence completely and by standard form.

\section{Language characteristics of the maritime English correspondence}

Language is the carrier of culture, and the culture is only embodied by the language. The intention to write the maritime correspondence is to communicate effectively, and let the other party clearly know what you want to say and grasp your intention, and quickly respond by simple expression and effective description. Through many years' development, the maritime English correspondence has formed its independent language system, with independent written requirements including courtesy, completeness, clarity, consideration, conciseness, concreteness, and correctness, which are called the principle of " $7 \mathrm{C}$ ". 


\subsection{Courtesy}

For courtesy, the polite vocabularies should be selected in phrase, and the language expression should be polite and unobtrusive, and the phrase should embody that you want to communicate with the other party, and let the other party know you truly want to cooperate with him, such as "your good company" and "your esteemed director". At the same time, the form should accord with the polite requirement, and the content should respect the other. For example, for the sentence "Do you think you could send us correct stowage factor?", literally, the meaning of this sentence is right, but it ignores that the sentence type of "Do you think you could" contains strong rhetorical question mood, and contains the meaning of doubting the other's ability, so the readers would read the "ironical" meaning, which doesn't accord with the polite requirements obviously. But if we change this sentence to "Would you please advise us correct stowage factor?", it will be a very hearty sentence, and thus request will be written back more possibly.

Different requirements of courtesy exist in different occasions, and the shipping industry involves many countries and departments, with internationalized characters, and different countries have different cultural backgrounds and different behavior modes, so the mode of courtesy has obvious national character. In the maritime English correspondence, employees should better know the other's history, tradition, evolvement, and various expression forms, and compare their cultural differences, and adopt different courtesy forms for different objects. For example, in Japanese, "SAN" is used for honorific title, so when communicating with Japanese clients, "XXX SAN" is better than "Dear XXX". At the same time, the courtesy should also consider both relationship, for example, "could/ would" is usually to denote very euphemistic and polite request between unfamiliar persons or those persons who first cooperate, but if the other party is good friend or the party cooperating for many years, "could/ would" will make the other party think that he is just an outsider, even induce misunderstanding. To respond the other's mail is the important part of the courtesy, and because of the difference of working time or other reasons, it is hard to correspond with the other's request in short time, but you can tell the other party that the correspondence has arrived, and the result will be informed as soon as possible.

\subsection{Completeness}

A maritime correspondence should completely express the meaning and content needed, which could be concretely measured by four "W" and one "H", i.e. When, Where, What, Who, and How to do. Above proceedings should be expressed clearly, and the content in the maritime correspondence should be very clear, and those proceedings which will bring the other party's misunderstanding or disputes should be more noticed. For example, one ship received the ship-owner's indication "Proceed to Fremental after unload" at certain port of Korea, and the captain checked that "Fremental" was one port of Australia from the "Guide to Port Entry", so he directed the ship to south, but in fact, the ship-owner required that the ship bear up to the Fremental Port of Canada, and the ship should went to the north, and after the ship had sailed for three days, it just found the misunderstanding, but it had worked six days' sailing sate losses and six days' oil consumption losses, and the ship-owner and the captain censure each other, and if the ship-owner could confirm the Fremental Port of Canada in the direction, above losses could be avoided completely.

\subsection{Clarity}

In the maritime English correspondence, all sentences and words should exactly express real intention, and simple and concise sentences and words should be used to directly tell the other party what is your meaning, and the double-meaningful and equivocal sentences and words should be avoided, and at the same time, following aspects should be noticed.

First, proper professional words should be selected. After many years' development, the maritime English correspondence has its own completed language system, and many professional words and acronyms have special meanings in the maritime English correspondence, and though these acronyms and professional glossaries are short, but they could exactly express the meanings. For example, to order fuels generally uses the word of "stem" in the maritime English correspondence, but if you use other words such as "order", "book", "purchase", and "buy" to denote "stem", the other party will easily think you want to buy other things, not fuels.

Second, the relative positions of various words should be noticed. The improper position of the word will express different meaning sometimes, so the relative position among words should be very clear. For example, "Not all cargoes to be discharged at this port" and "All cargoes not to be discharged at this port" have same words, but the positions of "not" are different, and two sentences express diametric meanings.

\subsection{Consideration}

In the maritime English correspondence, the "consideration" means that you should consider the other party, and express your meaning according to the other party's thinking mode, and only in this way, the communication with 
the other party could be effective. Specially, because of different starts, it is hard to avoid that both parties have different opinions, and when both opinions are different, the other party's opinion should be understood and respected first, and you should first consider the other party's start, and then give your opinion, and use relative proofs to prove your opinions, and should not blindly deny the other party's opinion, and if the other's requirement is not reasonable or the condemnation is obvious unjust, you should not blindly use offensive language, and in that way, both communication may be dead, and you should express your lofty stance and use the language that the other party could accept to argue on the basis of reason, and fully explain your opinions, and eliminate the difference by the communication. For example, the other party proposes one suggest which is very disadvantageous to you, and you can use "I don't think your proposal will be accepted", but not "Your proposal were totally rejected", and though both parties express save meaning, but the first expression indicates that both parties could further discuss the trade, and the possibility of cooperation still exists, and the second expression conceals the meaning that it is not necessary to further discuss the trade, and the possibility of further cooperation is very small, so you should adopt euphemistic, implicit, and facetious expression to denote different opinions for avoiding embarrassed situation. The "consideration" should also be embodied in the patience, and the employees in the maritime shipping enterprises would disposal many things every day, and sometimes they could not revert the other party in time because of various reasons, so when the other party could not give you a letter in reply in time, you should consider the other's difficulty and wait patiently, and should not assail the other party blindly.

\subsection{Conciseness}

Conciseness means that you should use possibly less words to express real meanings in the premise of integrity, concreteness, and courtesy, and the correspondence will be simple, concise, and easily understood. In the maritime English correspondence, holiday words are not needed, and the concise correspondence should come straight to the point, and let the other party clearly know what you want to say, and easily grasp your intention, and make the response very quickly. One lengthy correspondence with discursive start will make the other party feel bored, and don't have patient to read the whole correspondence, the writer's image will be discounted.

The words selected should be concise first, and the intention of the correspondence is to exactly and effectively transfer the information to the other party, and complex, uncommon, and flowery words could not only make the length of the correspondence be more tedious, and bring trouble to reader, but also select common words and avoid uncommon and complex words. For example, the sentence of "We will endeavor utilize chemical to clean holds on approximately March 15, so we place this order of 5 drums" is not only obscure, but also misunderstanding, because it uses several uncommon words, and "endeavor" could be replaced by "try", "approximately" could be replaced by "about", "utilize" could be replaced by "use", and "place this order of" could be replaced by "order". In same one correspondence, same word should be select to express similar meanings, for example, in the front, "goods have been sent" is written, here, "goods" means the meaning of "cargo", then only the "goods" should be used to denote "cargo" at the latter text, not other words such as "cargoes" and "commodity", or else, the unnecessary misunderstandings will be induced.

Second, the simple sentences should be selected. In the maritime English correspondence, some relative complex meanings are usually expressed, and if too long or complex sentences are selected, reader will not understand or induce misunderstanding, but the short sentence is easily understood, and many words such as "and", "but", "however", and "consequently" which could make the sentence become lengthy should be used less, and every topic should be better disjoined, which could make the other party more easily know the meaning what you want to express. For example, though the sentence of "We send you 5 NTM yesterday according to your requirement on your letter on May 20 by air" could express the meaning, but it is confused and hard to understood, and it is written by "Asp your message dated May 20, we express 5 NTM to you yesterday", and obviously, the latter sentence is more clear. When expressing relatively complex meaning, the simple sentence should be used as more as possibly.

Third, unnecessary repetitions should be avoided. Necessary repetition could be used to emphasize certain one opinion or important fact. But unnecessary repetition without any reason will make the reader be bored, so the unnecessary repetition in the correspondence written should be avoided as more as possibly. For example, in the sentence "Export shipping order will be ready sooner", "export" is repetitive. And the sentence of "We wish to acknowledge receipt of your letter" could be replaced by "We appreciate your letter" completely, and the sentence of "Enclosed herewith please find two copies of" could be completely replaced by "Enclosed two copies of".

\subsection{Concreteness}

Concreteness means that the content of the correspondence including time, place, price, and cargo number should be concrete and definite, and especially for the proceedings which need the other party's reply or relate to both parties' rights and obligations should be concreted to avoid disputes in the future. 


\subsection{Correctness}

Maritime English correspondence is the main approach and communication measure to associate business, communicate information, and replay consultation, and it represents both parties' benefits, and the content of the correspondence could be legal certificate and proof to solve the disputes. Sometime, one small written error could bring unnecessary trouble in the future, so the content must be correct. The correctness concludes not only expression, halting, and transliterating, but also standard language, proper depiction, exact numbers, and correct understandings about the shipping phrases. Good habit is that the correspondence should be checked from A to Z before it is sent, and once the correspondence with wrong information is found, you should send the correctness correspondence before the other party reply as soon as possibly to avoid troubles for both sides.

\section{The format requirements of the maritime English correspondence}

In the maritime English correspondence, concrete requirements are embodied not only in the content, but also in the format.

\subsection{Addressee (TO)}

"Addressee (TO)" means the name of the recipient company which needs to be responsible for the mail or assumes the reply responsibility, and when one correspondence is sent to one known company, this item must be filled in, and especially, company has its own public mailbox, and employees have their own private mails, and in normal working communication, the working things should not be sent to employees' private mailboxes.

\subsection{Attention}

"Attention" means the name of the employee who charges this business in the addressee, and when one mail has multiple addressees, above two items should be repeated.

\section{$3.3 \mathrm{Care} O \mathrm{OF} / \mathrm{CC}$}

"Care OF/CC" means the disputing party who needs to know the content of the mail, but needs not assume the responsibility of reply, and especially, when the addressee and the care of/cc are filled wrongly, addressee may misunderstood, which will influence the business communication.

\subsection{MSG Number}

"MSG Number" means the number of the correspondence, and generally employees should number each one correspondence, and in daily shipping business, the captain (or employees) would send tens or more correspondences with relative disputing parties (including the ship-owner, the management company, the sailor company, the port agency, the charterer, and the supplier), and for future inquiries, the addresser should number all mails which he sends in the day, and the number usually includes the data of the correspondence and the code name of the addresser (because the captain is the only person who has right to send the correspondence, so it could only contain the data), and the correspondence number could help us to check or cite the correspondence which has been sent in the future. For example, for the text of "Regarding this matter, please refer to my MSGNO051505", the other side could easily find relative answers in the fifth correspondence sent at May 15.

\subsection{Date}

"Date" means the data when the mail is sent.

\subsection{Object}

"Object" is the topic which should not only be concise but also show the emphases of the correspondence, and people should know the main content from the object, and especially, the shipping department will receive large numerous correspondences every day, and many of them are garbage mails, and employees usually judge whether they should open the mail by the object, and one correspondence being foreign to the business will usually be deleted as the garbage correspondence, so the object should be filled carefully and exactly.

\subsection{Salutation}

"Salutation" is a form of address to the addressee, and when you don't know the other party's name and sex, you can use "Dear Sirs" or "Dear Sirs and Madams". And when writing the correspondence to the addressee you have known, you should write the other party's name, or else, it is not polite. The shipping industry is the international industry, and the maritime correspondence has obviously international character, and because of the time difference, the time of addresser and the time of addressee are not consistent in many situations, so in the maritime correspondence, the usual salutation is GDTU "(short for Good Day to You)". 


\subsection{The body of the letter}

The body of the letter includes three parts, i.e. the front, the demonstration, and the end. The front generally should concisely tell the reader why the addresser writes this letter or be necessary self-introduction, and the demonstration should recite the fact or list the reasons to support the opinion of the first part in the letter, and the third part is to propose requirements or attention based on above expatiation, and the body of the letter is the core of the English correspondence, and the concrete written requirements are same with the above written requirements of the English correspondence.

\subsection{Complimentary close}

"Complimentary close" is a kind of holiday words to end the correspondence, and it should accord with the former salutation, such as "Sincerely", "Best Regards" or "Yours Truly".

\subsection{Enclosure}

If the enclosure is included in the correspondence, Encl. or Attached should be noted at the left bottom to denote the enclosure content, and remind addressee that the correspondence has the enclosure.

And the addressee, the date, the salutation, the body, and the complimentary close are necessary parts in the English correspondence, and the deficiency of other items may not influence the integrity of the correspondence, but one complete maritime English correspondence should include above items as more as possibly.

\section{Conclusions}

With the development of the shipping industry of China, the maritime English correspondence has been the important tool for the shipping enterprises to associate with foreign shipping enterprises and develop the shipping business and other business activities, and relative employees should quite be familiar with the written characters of the maritime English correspondence, and exactly grasp several basic principles in the written process, and write polite, implicit, euphemistic, and decent correspondences, to construct China as the big shipping country.

\section{References}

Qi, Zhiying. (2004). Business English Correspondence. Beijing: Mechanical Industry Press.

Shen, Jiang. (2007). Analysis of Maritime English Teaching and Strategy for Improvement. Maritime Education Research. No.4. P.32-34.

Wang, Jianping. (1998). Ocean Maritime English Written. Dalian: Dalian Maritime University Press.

Wang, Yuange. (2007). Commercial English Letters Written. Beijing: Beijing University Press.

Zhao, Bingbing. (2002). Brief Introduction to the Training of Maritime English. World Shipping. No.2. P.21-22. 